\title{
Rising to the Challenge of Unmet Need: Expanding the Lung Donor Pool
}

\author{
Aadil Ali $^{1} \cdot$ Shaf Keshavjee ${ }^{1,2} \cdot$ Marcelo Cypel $^{1,2}$ \\ Published online: 11 August 2018 \\ (C) Springer Science+Business Media, LLC, part of Springer Nature 2018
}

\begin{abstract}
Purpose of Review There is a shortage of lungs available to meet the needs of patient who require lung transplantation. Ex vivo lung perfusion (EVLP) has allowed for the assessment and reconditioning of extended criteria and high-risk donor lungs, allowing for an increased volume of lung transplants. Recently, an invested interest in the utilization donation after cardiac death (DCD) donors has surfaced, in which EVLP has played an important role.

Recent Findings Clinical studies have shown that EVLP can recondition donor lungs that initially would be unacceptable for transplantation. In a recent study, the intervention of EVLP was also shown to extend the window of total organ preservation time. Preclinical studies have shown promising results for EVLP to serve as a therapeutic platform to modulate inflammation, reduce edema, and treat infections and aspiration injuries. In addition, studies have shown the potential to recondition lungs of donation after cardiac death donors which suffer from additional injury in comparison to donation after brain death donors.

Summary EVLP is dynamic platform that can serve to treat and array of issues prior to transplantation. Indeed, the investigation of these therapeutic arsenals will soon allow physicians to expand the donor organ pool and improve transplantation outcomes.
\end{abstract}

Keywords Ex vivo lung perfusion $\cdot$ DCD donors $\cdot$ Reconditioning $\cdot$ Therapeutic platform $\cdot$ Lung transplantation

\section{Introduction}

For those with severe lung disease, lung transplantation (LTx) may be the only option for survival. Unfortunately, the current number of available donors is insufficient to meet patient waiting list needs. This is in part due to the low organ utilization rate of lungs available for transplantation. The percentage of lungs used from multi-organ donors is between 15 and $20 \%$, inferring that up to $85 \%$ of lungs are rejected in some regions for LTx [1]. Physicians are conservative of which lungs they select for transplant due to the potential risk of primary graft dysfunction (PGD) $[2,3]$. As a result, wait list mortalities can be as high as $30-40 \%$ [4-7]. Therefore, efforts to increase the number of lungs available for transplantation are attractive.

This article is part of the Topical Collection on Lungs Transplant

Marcelo Cypel

marcelo.cypel@uhn.ca

1 Latner Thoracic Surgery Research Laboratories, University Health Network, Toronto, ON, Canada

2 Toronto Lung Transplant Program, Toronto General Hospital, 200 Elizabeth St., 9N946, Toronto M5G 2C4, Ontario, Canada
One method that has aimed to serve this purpose is normothermic ex vivo lung perfusion (EVLP). This technique gives the opportunity to reassess lung function and recondition damaged lungs by providing physiological conditions to the graft. This review aims to provide a background to the EVLP technology and outline the progress that EVLP has made as a therapeutic platform to recondition marginal lungs.

\section{The Ex Vivo Lung Perfusion System}

Over the last 10 years, the number of LTxs performed annually has nearly doubled [8]. Although numerous factors contribute to this statistic, this can be partially attributed to several strides that haven been taken to enhance the management of donor organs prior to transplantation. One of these strides is the development of the EVLP system. Initial strategies using EVLP were only able to preserve the lung for $60 \mathrm{~min}$ before the development of circuit-induced lung injuries [9]. However, the Toronto technique has allowed for stable perfusion times for at least $12 \mathrm{~h} \mathrm{[10].} \mathrm{Since} \mathrm{the} \mathrm{development} \mathrm{of} \mathrm{technique} \mathrm{in}$ 2008, the amount of publications in the literature relating to EVLP have increased considerably as depicted in Fig. 1. 


\section{EVLP in the Literature}

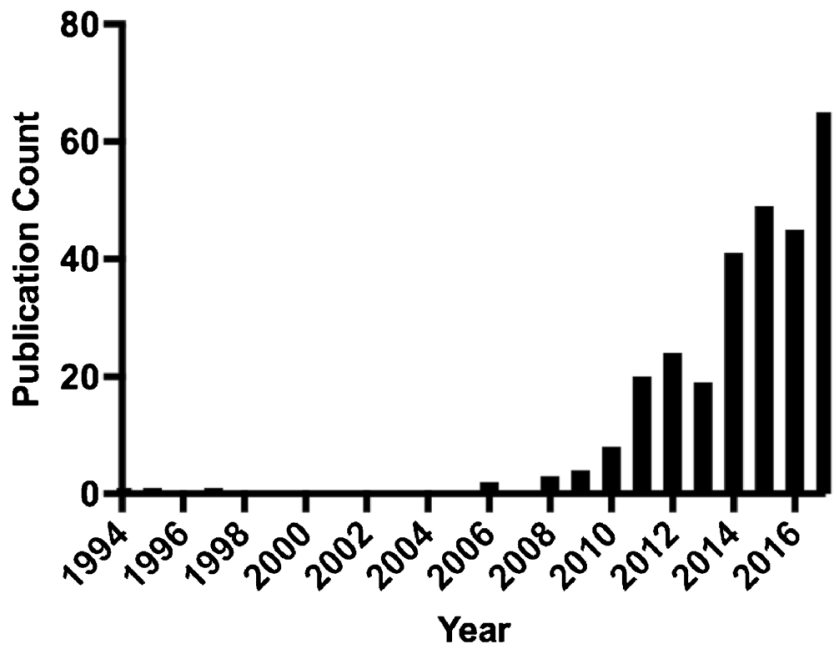

Fig. 1 A graphical depiction of the amount of publications relating to "ex vivo lung perfusion" yearly according to search results generated from Pubmed. Data was yearly plotted until 2017

Currently, three different EVLP methodologies have been described in the literature. These methodologies consist of Lund's protocol, Toronto's protocol, and the Organ Care System. Each perfusion protocol has their own unique strategies for flow, ventilation, and pressures which are outlined in Table 1. Each protocol has generated their own wealth of preclinical and clinical data.

\section{Reconditioning of Lungs Using EVLP}

As outlined previously, there are three different EVLP strategies being utilized worldwide. This section will describe the clinical experience of different centers using each specific protocol. In addition, Table 2 can be referenced to view the prospective clinical trials related to EVLP.

\section{The Toronto Protocol}

In 2011, the Toronto group published results from the first clinical trial related to EVLP in clinical transplantation. In this prospective, nonrandomized trial, lungs considered to be high risk for transplantation were subjected to $4 \mathrm{~h}$ of EVLP [11]. High-risk donor lungs were defined by specific criteria, including pulmonary edema, $\mathrm{P} / \mathrm{F}$ ratio of less than $300 \mathrm{mmHg}$, or other concerns [11]. Twenty-three donor lungs met the criteria to proceed to EVLP, and 20 of these were transplanted. No differences in PGD after $72 \mathrm{~h}$ was found in comparison to contemporary donors, and no differences were seen in 30-day mortality, bronchial complications, duration of mechanical ventilation, and length of stay in the intensive care unit and hospital [11].

In 2012, The Toronto group published a study sharing their experience with their first 50 EVLP clinical cases [12]. All 50 lungs were initially unsuitable for transplantation (defined as high-risk brain dead donors with a $\mathrm{PaO}_{2} / \mathrm{FIO}_{2}<300 \mathrm{mmHg}$ or
Table 1 Comparison of the ex vivo lung perfusion protocols used internationally in a clinical setting

\begin{tabular}{|c|c|c|c|}
\hline & \multicolumn{3}{|l|}{ Protocol } \\
\hline & Toronto & Organ Care System (OCS) & Lund \\
\hline \multicolumn{4}{|l|}{ Flow } \\
\hline Pump type & Centrifugal & Pulsatile & Roller \\
\hline Flow at start of perfusion & $10 \%$ cardiac output & $200 \mathrm{~mL} / \mathrm{min}$ & $100 \mathrm{~mL} / \mathrm{min}$ \\
\hline Target flow total & $40 \%$ cardiac output & $2.5 \mathrm{~L} / \mathrm{min}$ & $100 \%$ cardiac output \\
\hline \multicolumn{4}{|l|}{ Ventilation } \\
\hline Mode & Volume control & Volume control & Volume control \\
\hline Tidal volume & $7 \mathrm{~mL} / \mathrm{kg} \mathrm{BW}$ & $6 \mathrm{~mL} / \mathrm{kg} \mathrm{BW}$ & 5-7 mL/kg BW \\
\hline Frequency & 7 bpm & $10 \mathrm{bpm}$ & $20 \mathrm{bpm}$ \\
\hline PEEP & $5 \mathrm{~cm} \mathrm{H}_{2} \mathrm{O}$ & $5 \mathrm{~cm} \mathrm{H}_{2} \mathrm{O}$ & $5 \mathrm{~cm} \mathrm{H}_{2} \mathrm{O}$ \\
\hline $\mathrm{FiO}_{2}$ & $21 \%$ & $21 \%$ & $50 \%$ \\
\hline \multicolumn{4}{|l|}{ Pressure } \\
\hline Pulmonary artery & $<15 \mathrm{mmHg}$ & $<20 \mathrm{mmHg}$ & $<20 \mathrm{mmHg}$ \\
\hline Left atrium & 3-5 mmHg (closed) & 0 mmHg (open) & 0 mmHg (open) \\
\hline \multicolumn{4}{|l|}{ Target temperature } \\
\hline & $37^{\circ} \mathrm{C}$ & $37^{\circ} \mathrm{C}$ & $37^{\circ} \mathrm{C}$ \\
\hline Perfusion solution & $\mathrm{STEEN}^{\mathrm{TM}}$ solution & $\begin{array}{l}\text { OCS }^{\mathrm{TM}} \text { solution + red } \\
\text { cells }(\text { Hct } 15-25 \%)\end{array}$ & $\begin{array}{l}\text { STEEN }^{\mathrm{TM}} \text { solution + red } \\
\text { cells }(\text { Hct } 14 \%)\end{array}$ \\
\hline Total perfusion time & $4-6 \mathrm{~h}$ & Transport time & $2 \mathrm{~h}$ \\
\hline
\end{tabular}

PEEP positive-end expiratory pressure, $\mathrm{bpm}$ breathes per minute, $\mathrm{Hct}$ hematocrit, $\mathrm{FiO}_{2}$ fraction of inspired oxygen, $B W$ body weight 
Table 2 Prospective clinical trials using ex vivo lung perfusion

\begin{tabular}{lllll}
\hline Trial name & Identifier no. & EVLP indication & Protocol & Status \\
\hline HELP & NCT01190059 & Extended & Toronto & Completed \\
NOVEL & NCT01365429 & Extended & Toronto & Recruiting \\
INSPIRE & NCT01630434 & Standard & OCS & Recruiting \\
EXPAND & NCT01963780 & Extended & OCS & Recruiting \\
DEVELOP & N/A & Extended & Lund & Completed \\
Vienna & N/A & Extended & Toronto & Completed \\
Lung bioengineering & NCT02234128 & Extended & Toronto & Recruiting \\
EXPAND II & NCT03343535 & Extended & OCS & Not yet recruiting \\
Bergamo & NCT03053349 & Extended & Toronto & Recruiting \\
EVLP_MI & NCT01967953 & Extended & OCS & Completed \\
EVLP-CHUM & NCT02235610 & Extended & Lund & Recruiting \\
Hopital Foch & NCT02906436 & Extended & Toronto & Completed \\
HCV pilot study & NCT03112044 & Extended/HCV & Toronto & Recruiting \\
\hline
\end{tabular}

lungs with radiographic or clinical findings of pulmonary edema or lungs from cardiac death donors), however, were reconditioned to meet acceptable transplantation criteria. Patients who received these lungs achieved 1-year survival rates similar to conventional transplant patients, as well as an equivalent duration of mechanical ventilation, hospitalization time, intensive care unit stay, and incidence of PGD grade 3 at 72 h [12]. In 2015, Machuca et al. published Toronto's initial efforts to use lungs from donation after cardiac death (DCD) donors. Within a 6-year span, over $50 \%$ of DCD lungs were placed on the EVLP circuit for evaluation prior to Ltx. The study found that lungs transplanted from these donors share a similar 1- and 5-year survival to donation after neurological determination of death. Interestingly, it was found that patients that received lungs from DCD donors that underwent EVLP prior to LTx versus those that did not had a shorter hospital stay and trended towards a shorter length of mechanical ventilation [13]. In 2015, the Toronto group published the functional outcomes and quality of life of patients who received lungs that underwent EVLP. The study showed equivalent 1-, 3-, and 5-year survival rates in comparison to recipients who received lungs from conventional donors, as well as similar freedom from chronic lung allograft dysfunction [14]. In addition, no differences in functional outcomes such as highest forced expiratory volume in $1 \mathrm{~s}$, change in 6-min walk distance, and acute rejection episodes were reported [14].

The Vienna group published a prospective study which showed the utilization of high-risk donors within their center. In this study, they show a median donor $\mathrm{PaO}_{2}$ of $216 \mathrm{mmHg}$ which improved to a median $\mathrm{PvO}_{2}$ of $466 \mathrm{mmHg}$ at the final assessment of EVLP [15]. No patients developed grade 2 or 3 PGD, and patients showed no 30-day mortality [15].

Boffini et al. from Torino evaluated the incidence of PGD after LTx using rejected lungs reconditioned using EVLP within their center. There were no differences in the occurrence of PGD between lungs reconditioned using EVLP and lungs from conventional donors at the 0 - and 72-h assessment time point [16].

In 2014, Sage et al. published the French EVLP experience. During EVLP, 31 out of 32 lungs initially rejected for transplant recovered from a $\mathrm{PO}_{2} / \mathrm{FiO}_{2}$ ratio of 274 to 511 [17]. There were no significant differences in PGD incidence after $72 \mathrm{~h}$, median extubation time, intensive care unit and hospital lengths of stay, 30-day mortality, and 1year survival rates [17].

The Harefield group published a retrospective review of 13 consecutive EVLP over a span of a little under 2 years. The six transplanted patients showed similar early, 3-month, and 6month survival rates and ICU and hospital length of stay to their contemporary transplant population [18].

In addition, EVLP has been shown to allow for the extension of total organ preservation time. This extended amount of time can allow for the achievement of increased organ transportation distances as well as longer therapeutic windows for organ reconditioning. In a recent retrospective study, Yeung et al. explored the outcomes of patients who received LTxs with lungs that had been preserved for greater than $12 \mathrm{~h}$ as a result of EVLP intervention in comparison to patients who received conventional lungs that were preserved for less than $12 \mathrm{~h}$ [19••]. Early post-transplant outcomes were similar between the two groups despite high-risk lungs. In addition, no differences were seen in primary graft dysfunction or length of hospital and ICU stay between the two groups. Patients apart of the extended preservation group had no difference in survival compared to patients who received lungs that were preserved for less than $12 \mathrm{~h}$. These results are extremely encouraging, as lifesaving transplants can now be performed across larger geographic areas without the risk of poorer outcomes. 


\section{The Lund Protocol}

In 2001, Steen et al. published the first case report of using the EVLP platform as an assessment tool to transplant a DCD donor [20]. In 2007, Steen et al. described the first human transplantation of a nonacceptable donor lung after reconditioning from EVLP. The donor lung $\mathrm{PaO}_{2}$ was just $67.5 \mathrm{mmHg}$ on $\mathrm{FiO}_{2}$ of 0.7 , even after ventilator treatment and attempts to clean the airways. The left lung was reconditioned ex vivo and then stored in a cooled EVLP perfusate with added buffered Perfadex and topical oxygenation from a membrane until transplantation [21]. The patient showed good recovery, and after 3 months, a computed tomographic thoracic scan and transbronchial biopsies showed a normal left lung [21].

In 2014, Henriksen et al. shared the first Danish experience using EVLP. In the study period, seven of 33 Danish lung transplantations were made possible due to EVLP. All lungs showed an improved median $\mathrm{P} / \mathrm{F}$ ratio, which corresponded to $155 \%$ improved oxygenation. No patients died to EVLPrelated causes by the end of the registration period [22].

In the same year, Wallinder et al. published the EVLP experience from the Gothenburg group. In this case-control study, 11 donor lungs were proceeded to EVLP due to either inferior $\mathrm{P} / \mathrm{F}$ ratio, bilateral infiltrate on chest $\mathrm{X}$-ray, or ongoing extracorporeal membrane oxygenation [23]. Donor grafts showed improved oxygenation during EVLP [23]. The authors found a longer median time to extubation and median intensive care unit stay to be significantly higher in recipients receiving lungs from the EVLP groups, versus contemporary controls [23]. Despite this finding, no difference was seen in length of hospital stay, and all recipients of EVLP lungs were discharged alive [23].

\section{OCS Protocol}

In 2012, Warnecke et al. published the initial experience of Madrid and Hanover groups using EVLP for lung preservation, assessment, and transport. In this pilot study, 12 standard donor lungs were perfused using the OCS protocol. No significant improvements were shown in the $\mathrm{P} / \mathrm{F}$ ratio of the graft during EVLP; however, all recipient patients survived to 30 days, recovered, and were discharged from hospital [24]. These findings showed safe pulmonary preservation using the OCS technique.

In 2014, the Leuven group published a successful case report of a combined liver-lung transplantation. Lungs were subjected to EVLP in order to strategize for longer preservation times. The lungs were perfused for a total time of $675 \mathrm{~min}$ [25]. The patient was extubated 7 days after the surgery, and no rejection was seen 10 months later [25].

Mohite et al. published the first report in which the OCS system was used strictly for lung assessment. In this case report, lungs from a DCD donor was placed on the circuit, in which the P/F ratio showed improvements over time [26]. Bilateral transplantation was performed and the patient was extubated in $24 \mathrm{~h}$, moved to the ward in $48 \mathrm{~h}$, and discharged at 14 days [26]. The patient showed good lung function at a 6month follow-up [26].

\section{Ex Vivo Lung Perfusion as a Therapeutic Platform}

Besides lung assessment and preservation, EVLP provides a platform for the use of a variety of therapeutic applications in which donor-specific issues can be addressed prior to Ltx. Within the platform, the lungs can be treated systemically by supplementing the perfusion solution, or intratracheally through bronchoscopic administration. We will outline a few key studies which have shown the use of therapeutic agents within the ex vivo circuit.

\section{Immunomodulation}

The development of PGD is responsible for lower survival rates in LTx patients, leading to approximately $20-30 \%$ mortality within the first month after transplantation $[8,27]$. Although the etiology of PGD is still currently being investigated, the development seems to be correlated with initial injuries of the graft. An early contributor in aggregating these injuries is the initial phase of reperfusion, a phenomenon known as ischemia-reperfusion injury. Although the precise mechanism of ischemia-reperfusion injury is still unknown, previous studies have shown a rapid release of endogenous inflammatory mediators at the onset of reperfusion [28, 29]. Promoting an anti-inflammatory environment prior to transplantation may therefore be effective in reducing lung injury. In 2009, Cypel et al. investigated the functional repair of human donor lungs using interleukin-10 (IL-10) gene therapy [30]. IL-10 is an anti-inflammatory cytokine that has been shown to reduce the release of pro-inflammatory cytokines [31]. In this study, the authors delivered adenoviral vector encoding human IL-10 bronchoscopically to human lungs rejected for transplantation using the EVLP platform. Throughout the $12 \mathrm{~h}$ of perfusion, the lungs showed significant improvements in pulmonary vascular resistance, alveoli oxygenation capabilities, and a favorable switch in cytokine expression [30].

Another potential therapeutic approach to modulate cytokine activity is through the use of mesenchymal stem cell (MSC)-based therapy. MSCs are well known to play an immunomodulatory role by migrating to sites of inflammations, in which they participate in cell-to-cell interactions or secrete soluble factors. The specific mechanisms of immunomodulation have been reported to be avoiding 
allorecognition, interfering with dendritic cell and $\mathrm{T}$ cell function and generating a local immunosuppressive microenvironment by secreting cytokines [32]. The optimal administration route was investigated for the delivery of MSCs during EVLP. In this study, the authors found that intravenous delivery (in the perfusate) demonstrated greater efficacy than instillation through the airways within a swine model [33]. In addition, the authors found a decrease in circulating IL-8 levels during EVLP, which has been previously shown to be an inflammatory marker of ischemia-reperfusion injury [29, 34]. Lee et al. investigated the use of MSCs to recover endotoxin-induced acute lung injury within donor human lungs rejected for transplantation. In this study, the authors showed significantly less neutrophil influx in the injured lungs which were treated with MSCs [35].

\section{Aspiration Injury}

Gastric aspiration within donor lungs can be a crucial factor for declining a lung for transplant. Indeed, aspiration injury has been shown to lead to different pulmonary complications such as aspiration pneumonitis [36]. The EVLP platform has been used to treat aspiration-induced lung injury using large animal models. In 2008, Inci et al. put forth an aspirationinjury model which they instilled a mixture of betaine-HCl/ pepsin into the airways [37]. In this model, they tested whether a surfactant lavage administered during EVLP could recover physiologic parameters. Surfactant lavage during EVLP resulted in a higher $\mathrm{PaO}_{2} / \mathrm{FiO}_{2}$ ratio, and lower pulmonary vascular resistance [37]. In 2011, Meers et al. described a model of aspiration-induced injury by instilling gastric juice into the airways, rather than an acidic substitute mixture [38]. Using a similar gastric juice-induced lung injury model, it was later shown that exogenous surfactant administered immediately before EVLP was able to improve $\mathrm{PaO}_{2}$, lower pulmonary vascular resistance, and decrease the amount of apoptotic cell death [39•]. In 2016, the Toronto group published a study evaluating the lung lavage followed by exogenous surfactant administration in a gastric juice-induced lung injury model. In their study, they showed that this therapeutic intervention reduced the number of circulating inflammatory cytokines found within the recipient pig's plasma, and also led to superior post-transplant lung function in comparison to controls, represented by a greater $\mathrm{PaO}_{2} / \mathrm{FiO}_{2}$ ratio $\left[40^{\bullet}\right]$.

\section{Infection}

The presence of bacteria and other pathogens can potentially injure lungs and lead to sepsis in recipient patients. Between 46 and $89 \%$ of the donor lungs have positive bronchoalveolar lavage bacterial cultures [41]. Removal of these species may be advantageous in preventing these potentially negative outcomes. Researchers have aimed to use the platform in order to clear infections prior to transplanting these lungs. In a study done by Andreasson et al., 18 human lung donors considered unusable for transplantation underwent EVLP with a perfusate containing high-dose, empirical, broad-spectrum anti-microbial agents. Out of the 18 lungs, 13 of them had positive bacteria cultures (72\%), in which the bacterial load significantly decreased during EVLP [42]. In addition, the researchers showed that adding anti-fungal treatment was also able to decrease yeast loads [42]. Ultimately, they deemed six lungs suitable for transplantation, in which all patients survived hospital discharge [42].

In 2016, Nakajima et al. published a study randomizing donor human lungs rejected for transplantation due to the clinical concern of infection to receive $12 \mathrm{~h}$ of convention perfusion, or perfusion supplemented with high-dose antibiotics. A quantitative decrease in bacterial counts in bronchoalveolar lavage was found in all antibiotic-treated cases; however, this result was only seen in two control cases. Perfusate endotoxin levels at $12 \mathrm{~h}$ were significantly lower in the antibiotic group compared with the control group [43•]. In addition, the treatment group showed significant improvements in pulmonary oxygenation and compliance and reduced pulmonary vascular resistance during EVLP [43•].

In a recent publication, Zinne et al. put forth a Pseudomonas aeruginosa pneumonia model. In this model, this multidrug resistant bacterium was instilled within the lower lobes of mini-Lewe pigs [44••]. The authors investigated whether $2 \mathrm{~h}$ of EVLP using circulating colistin followed by autotransplantation could be advantageous in comparison to conventional methods of daily intravenous colistin administration and controls. In the control and conventional treatment groups, the mortality rate related to infection after 5 days was $66.7 \%$ [44••]. However, in the EVLP group, there was only one infection-related mortality and one procedure-related mortality, resulting in an overall mortality rate of $33.3 \%$ [44*0]. In addition, the authors found that lungs treated with EVLP displayed less clinical symptoms of infection [44••].

\section{Pulmonary Edema}

Weakening of the endothelial-fluid barrier results in leakage of fluid into the interstitial space, and ultimately across the lung endothelial cells into the alveolar space. Removal of edema fluid from the air spaces is dependent on a transepithelial sodium concentration gradient established by basolateral sodium-potassium ATPase [45]. Studies have shown that the rate of alveolar epithelial ion and fluid transport can be upregulated through the use of $\beta_{2}$-adrenergic agonists [46, 47]. Franck et al. showed that by putting human lungs rejected for transplantation on the EVLP circuit, there was a natural alveolar fluid clearance and reduction in pulmonary edema [48]. In addition, by adding a $\beta_{2}$-selective adrenergic agonist 
(terbutaline) to the EVLP perfusate, rates increased significantly by more than twofold [48].

Along a similar idea, another group tested whether a $\beta$ adrenergic receptor agonist (salbutamol) which is known to upregulate fluid transport in the lung would be effective in reducing pulmonary edema [49]. Their primary indicator of edema formation was lung glucose consumption during EVLP, which they validated within a previous study [50]. In the study, the authors randomized donor pig lungs to salbutamol infusion during EVLP, or a placebo. The results showed that glucose concentration in the perfusate was affected by salbutamol, and salbutamol infusion was associated with lower pulmonary pressures and better lung mechanics [49].

In 2015, Kondo et al. investigated whether an aerosolized $\beta 2$-adrenoreceptor agonist delivered through the airways during EVLP could improve lung physiology in a beagle EVLP model [51]. In comparison to the control group, the treatment showed significantly less lung edema measured by tissue wetto-dry ratios [51]. This was correlated with greater cystic fibrosis transmembrane regulator (CFTR) gene expression [51].

\section{Pulmonary Emboli}

In organ donation, donors run the risk of developing venous thromboemboli. This can be critical as pulmonary emboli have been associated with poor early outcomes in lung transplant recipients [52]. EVLP serves as an opportunity to apply anti-thrombotic agents in order to remove these emboli prior to transplant. The first case report was published by Machuca et al. A donor with severe PE was treated with alteplase during EVLP - a known thrombolytic agent [53]. Improvements in pulmonary artery pressure and pulmonary vascular resistance during EVLP indicated successful thrombolysis, and the lungs proceeded to clinical transplantation [53]. In 2015, another case report was published showing alteplase as a successful adjunct for thrombolysis during EVLP, leading to subsequent clinical LTx [54]. Urokinase, a known plasminogen activator, has also shown positive results in the treatment of pulmonary emboli [55].

\section{Donation After Cardiac Death}

As mentioned previously, the limited number of donor organs available for transplantation is a major hurdle faced within the field [1]. Traditional organ donation has been only from those who have died after meeting brain death criteria, referred to as donation after brain death (DBD) donors. Within the last couple of decades, there has been a growing interest in utilizing lungs from donation after cardiac death (DCD) donors in order to expand the number of available organs $[56,57]$. DCD donors can be categorized into two subclasses according to
Maastricht classification: controlled DCD (cDCD) donors and uncontrolled DCD donors ( $\mathrm{UDCD}$ ). $\mathrm{cDCD}$ patients experience a period of hypoxia, warm ischemia, aspiration injury, or hypotension during the time between the removal of life support and organ retrieval. The current tolerated time of this interval is still an ongoing discussion within the field. In contrast, $\mathrm{uDCD}$ donors can be brought in dead, experience an unsuccessful resuscitation, arrest after brain-stem death, or arrest as an inpatient. These donors experience similar deleterious effects prior to organ procurement.

A recent report from the International Society of Heart and Lung Transplantation (ISHLT) showed 300+ transplants performed using DCD donors among 10 centers [58]. Indeed, most clinical reports have recently showed equivalent posttransplant outcomes between recipients who received lungs from DCD versus those from conventional DBD donors [15, 58-70]. Although cDCD transplantation have been shown to succeed using conventional assessment techniques and protocols, EVLP is a great tool to expand DCD utilization as it allows a final assessment of the organ which is vulnerable to injuries during the time of withdrawal of life support in ICU. In 2001, Steen et al. reported a successful single LTx of a DCD donor in which they evaluated the lung using an earlier model of the EVLP system [20]. In 2015, Machuca et al. showed that transplantation of lungs of DCD donors had a greater efficacy if they were subjected to EVLP. In this retrospective study, patients who received lungs under these conditions had a significantly shorter hospital stay in comparison to lungs from DCD donors that went straight to LTx, and trended towards a shorter length of mechanical ventilation [13].

Different adjunct therapies have been proposed in order to facilitate the reconditioning of these high-risk donor lungs during EVLP. Indeed, the next step towards the utilization of these donors is to further minimize the risk of PGD during transplantation, and to adapt novel strategies to extend the allowable time during warm ischemia. In a previous section of this paper, we describe the use of fibrinolytic agents in order to reduce the risk of potential pulmonary emboli in recipients from lungs of DCD donors [53, 55]. Additional strategies have also been actively investigated to treat DCD lungs during EVLP, however still remain in pre-clinical stages. One of these strategies includes the administration of organoprotective gases during lung ventilation on the EVLP circuit. In theory, these gases should provide anti-oxidant and anti-inflammatory effects, allowing for enhanced reconditioning of injured lungs. Therapeutic gases that have been explored include hydrogen, carbon monoxide, xenon, and argon gas [71-73]. Although improved graft function was not shown when using xenon or argon gas, positive results were shown upon the administration of hydrogen gas or carbon monoxide during EVLP. These results call for continued exploration of therapeutic gases to recondition $\mathrm{DCD}$ donor lungs. 
Recently, Martens et al. have shown the use of steroids as a treatment during warm ischemic time and during EVLP [74]. In this study, $500 \mathrm{mg}$ methylprednisolone was given prior to cardiac arrest and during EVLP. In the control group, no steroids were added. The use of steroids improved cytokine profiles, wet-to-dry ratios, and lung density.

Previous experimental studies have shown that surfactant function decreased with prolonged warm ischemia [75]. In a DCD model followed by an artificial aspiration injury, a surfactant lavage was given during EVLP, and the lungs proceeded to LTx. The transplanted graft showed better oxygenation, lower mean pulmonary artery pressure, and lower lung edema [76]. In the bronchoalveolar lavage taken at the end of the experiment, the percentage of neutrophils, IL-1 beta, and IL-6 cytokine levels were significantly lower in the surfactant group compared to controls [76].

In a murine DCD EVLP model, Huerter et al. administered a selective A2B receptor antagonist during lung perfusion in hopes to facilitate reconditioning of lungs damaged from warm ischemia. The A2B receptor been shown to play a pro-inflammatory role in ischemia-reperfusion lung injury [77]. Administration of the A2B receptor antagonist resulted in increased compliance and reduced pulmonary artery pressure during EVLP, in comparison to lungs that did not receive this treatment [78]. A similar concept of reconditioning DCD lungs during EVLP by attenuating a factor within the ischemia-reperfusion lung injury pathway was published in a rat EVLP model by Francioli et al. The authors hypothesized that DCD lungs might be treated during EVLP by pyrrolidine dithiocarbamate (PDTC), an inhibitor of NF- $\mathrm{KB}$, which has been shown to play an instrumental role in acute inflammation [79]. The study found that treatment with PDTC during EVLP inhibited NF-KB activation, markedly reduced lung edema, suppressed TNF $\alpha$ and IL- 6 release, and abrogated the changes in lung static compliance, peak airway pressures, and pulmonary vascular resistance [79]. These studies suggest that EVLP can serve a specific platform to mediate lung inflammation, and to aid in the reconditioning and repair of marginal lungs offered from DCD donors.

\section{Conclusions}

We identify the potential of EVLP to recondition lungs to allow for the expansion of the current donor pool. Attempts have been made to manage and reverse inflammation, aspiration injury, edema, and infection using the EVLP system. In addition, complications in DCD donor lungs have been effectively reduced through the opportunity to asses and recondition high-risk lungs during EVLP. Pre-clinical studies are promising in order to recover more rejected lungs using EVLP.

\section{Compliance with Ethical Standards}

Conflict of Interest Marcelo Cypel and Shaf Keshavjee are co-founders of Perfusix Inc. and XOR Labs Toronto (companies related to ex vivo organ perfusion) and consultants to lung bioengineering. Ali Aadil reports no conflict of interest.

Human and Animal Rights and Informed Consent This article does not contain any studies with human or animal subjects performed by any of the authors.

\section{References}

Papers of particular interest, published recently, have been highlighted as:

- Of importance

-• Of major importance

1. Punch JD, Hayes DH, Laporte FB, McBride V, Seely MS. Organ donation and utilization in the United States, 1996-2005. Am J Transplant. 2007;7:1327-38.

2. de Perrot M, Liu M, Waddell TK, Keshavjee S. Ischemiareperfusion-induced lung injury. Am J Respir Crit Care Med. 2003;167:490-511.

3. Diamond JM, Lee JC, Kawut SM, Shah RJ, Localio AR, Bellamy SL, et al. Clinical risk factors for primary graft dysfunction after lung transplantation. Am J Respir Crit Care Med. 2013;187:52734.

4. De Meester J, Smits JMA, Persijn GG, Haverich A. Listing for lung transplantation: life expectancy and transplant effect, stratified by type of end-stage lung disease, the Eurotransplant experience. J Hear Lung Transplant. 2001;20:518-24.

5. Lederer DJ, Arcasoy SM, Wilt JS, D'Ovidio F, Sonett JR, Kawut SM. Six-minute-walk distance predicts waiting list survival in idiopathic pulmonary fibrosis. Am J Respir Crit Care Med. 2006;174: 659-64.

6. Titman a RC a, Bonser RS, Banner NR, Sharples LD. Diseasespecific survival benefit of lung transplantation in adults: a national cohort study. Am J Transplant. 2009;9:1640-9.

7. Valapour M, Paulson K, Smith JM, Hertz MI, M a S, Heubner BM, et al. OPTN/SRTR 2011 Annual Data Report: lung. Am J Transplant 13 Suppl. 2013;1:149-77.

8. Yusen RD, Edwards LB, Dipchand AI, Goldfarb SB, Kucheryavaya AY, Levvey BJ, et al. The registry of the International Society for Heart and Lung Transplantation: thirtythird adult lung and heart-lung transplant report-2016; focus theme: primary diagnostic indications for transplant. J Hear Lung Transplant. 2016;35:1170-84.

9. Erasmus ME, Fernhout MH, Elstrodt JM, Rakhorst G. Normothermic ex vivo lung perfusion of non-heart-beating donor lungs in pigs: from pretransplant function analysis towards a 6-h machine preservation. Transpl Int. 2006;19:589-93.

10. Cypel M, Yeung JC, Hirayama S, Rubacha M, Fischer S, Anraku $\mathrm{M}$, et al. Technique for prolonged Normothermic ex vivo lung perfusion. J Hear Lung Transplant. 2008;27:1319-25.

11. Cypel M, Yeung JC, Liu M, Anraku M, Chen F, Karolak W, et al. Normothermic ex vivo lung perfusion in clinical lung transplantation. N Engl J Med. 2011;364:1431-40.

12. Cypel M, Yeung JC, Machuca T, Chen M, Singer LG, Yasufuku K, et al. Experience with the first 50 ex vivo lung perfusions in clinical transplantation. J Thorac Cardiovasc Surg. 2012;144:1200-7. https://doi.org/10.1016/j.jtcvs.2012.08.009. 
13. Machuca TN, Mercier O, Collaud S, Tikkanen J, Krueger T, Yeung $\mathrm{JC}$, et al. Lung transplantation with donation after circulatory determination of death donors and the impact of ex vivo lung perfusion. Am J Transplant. 2015;15:993-1002.

14. Tikkanen JM, Cypel M, Machuca TN, et al. Functional outcomes and quality of life after normothermic ex vivo lung perfusion lung transplantation. J Hear Lung Transplant. 2014;34:1-10.

15. Aigner C, Slama A, Hötzenecker K, Scheed A, Urbanek B, Schmid $\mathrm{W}$, et al. Clinical ex vivo lung perfusion - pushing the limits. Am J Transplant. 2012;12:1839-47.

16. Boffini M, Ricci D, Bonato R, Fanelli V, Attisani M, Ribezzo M, et al. Incidence and severity of primary graft dysfunction after lung transplantation using rejected grafts reconditioned with ex vivo lung perfusion. Eur J Cardiothorac Surg. 2014;46:789-93.

17. Sage E, Mussot S, Trebbia G, Puyo P, Stern M, Dartevelle P, et al. Lung transplantation from initially rejected donors after ex vivo lung reconditioning: the French experience. Eur J Cardio-thoracic Surg. 2014;46:794-9.

18. Zych B, Popov AF, Stavri G, Bashford A, Bahrami T, Amrani M, et al. Early outcomes of bilateral sequential single lung transplantation after ex-vivo lung evaluation and reconditioning. J Hear Lung Transplant. 2012;31:274-81.

19.•• Yeung JC, Krueger T, Yasufuku K, de Perrot M, Pierre AF, Waddell TK, et al. Outcomes after transplantation of lungs preserved for more than $12 \mathrm{~h}$ : a retrospective study. Lancet Respir Med. 2016;2600:1-6. Publication showing that EVLP can increase total safe preservation times.

20. Steen S, Sjöberg T, Pierre L, Liao Q, Eriksson L, Algotsson L. Transplantation of lungs from a non-heart-beating donor. Lancet. 2001;357:825-9.

21. Steen S, Ingemansson R, Eriksson L, Pierre L, Algotsson L, Wierup $\mathrm{P}$, et al. First human transplantation of a nonacceptable donor lung after reconditioning ex vivo. Ann Thorac Surg. 2007;83:2191-4.

22. Iversen Henriksen IS, Møller-Sørensen H, Holdflod Møller C, Zemtsovski M, Christian Nilsson J, Tobias Seidelin C, et al. First Danish experience with ex vivo lung perfusion of donor lungs before transplantation. Dan Med J. 2014;61:A4809.

23. Wallinder A, Ricksten SE, Silverborn M, Hansson C, Riisec GC, Liden $\mathrm{H}$, et al. Early results in transplantation of initially rejected donor lungs after ex vivo lung perfusion: a case-control study. Eur J Cardio-Thoracic Surg. 2014;45:40-5.

24. Warnecke G, Moradiellos J, Tudorache I, Kühn C, Avsar M, Wiegmann B, et al. Normothermic perfusion of donor lungs for preservation and assessment with the organ care system lung before bilateral transplantation: a pilot study of 12 patients. Lancet. 2012;380:1851-8.

25. Ceulemans LJ, Monbaliu D, Verslype C, van der Merwe S, Laleman W, Vos R, et al. Combined liver and lung transplantation with extended normothermic lung preservation in a patient with end-stage emphysema complicated by drug-induced acute liver failure. Am J Transplant. 2014;14:2412-6.

26. Mohite PN, Sabashnikov A, García Sáez D, Pates B, Zeriouh M, De Robertis F, et al. Utilization of the organ care system lung for the assessment of lungs from a donor after cardiac death (DCD) before bilateral transplantation. Perfus (United Kingdom). 2015;30:427-30.

27. Bharat A, Narayanan K, Street T, Fields RC, Steward N, Aloush A, et al. Early posttransplant inflammation promotes the development of alloimmunity and chronic human lung allograft rejection. Transplantation. 2007;83:150-8.

28. Kaneda H, Waddell TK, De Perrot M, Bai XH, Gutierrez C, Arenovich T, et al. Pre-implantation multiple cytokine mRNA expression analysis of donor lung grafts predicts survival after lung transplantation in humans. Am J Transplant. 2006;6:544-51.

29. De Perrot M, Sekine Y, Fischer S, Waddell TK, Mcrae K, Liu M, et al. Interleukin- 8 release during early reperfusion predicts graft function in human lung transplantation. Am J Respir Crit Care Med. 2002;165:211-5.

30. Cypel M, Liu M, Rubacha M, et al. Functional repair of human donor lungs by IL-10 gene therapy. Sci Transl Med. 2009;1:4ra9.

31. Moore KW, De Waal Malefyt R, Coffman RL, O 'garra A. Interleukin-10 and the Interleukin-10 receptor. Annu Rev Immunol. 2001;19:683-765.

32. Ryan JM, Barry FP, Murphy JM, Mahon BP. Mesenchymal stem cells avoid allogeneic rejection. J Inflamm (Lond). 2005;2(8):8.

33. Mordant P, Nakajima D, Kalaf R, Iskender I, Maahs L, Behrens P, et al. Mesenchymal stem cell treatment is associated with decreased perfusate concentration of interleukin- 8 during ex vivo perfusion of donor lungs after 18-hour preservation. J Hear Lung Transplant. 2016;35:1245-54.

34. Mordant P, Nakajima D, Kalaf R, et al. Mesenchymal stem cell treatment is associated with decreased perfusate concentration of IL-8 during ex vivo perfusion of donor lungs after $18 \mathrm{~h}$ preservation. J Hear Lung Transplant. 2016:1-10.

35. Lee JW, Fang X, Gupta N, Serikov V, Matthay MA. Allogeneic human mesenchymal stem cells for treatment of E. Coli endotoxininduced acute lung injury in the ex vivo perfused human lung. Proc Natl Acad Sci U S A. 2009;106:16357-62.

36. Marik PE. Aspiration pneumonitis and aspiration pneumonia. $\mathrm{N}$ Engl J Med. 2001;344:665-71.

37. Inci I, Ampollini L, Arni S, Jungraithmayr W, Inci D, Hillinger S, et al. Ex vivo reconditioning of marginal donor lungs injured by acid aspiration. J Hear Lung Transplant. 2008;27:1229-36.

38. Meers CM, Tsagkaropoulos S, Wauters S, Verbeken E, Vanaudenaerde B, Scheers H, et al. A model of ex vivo perfusion of porcine donor lungs injured by gastric aspiration: a step towards pretransplant reconditioning. J Surg Res. 2011;170:e159-67.

39. Khalife-Hocquemiller T, Sage E, Dorfmuller P, Mussot S, Le Houerou D, Eddahibi S, et al. Exogenous surfactant attenuates lung injury from gastric-acid aspiration during ex vivo reconditioning in pigs. Transplantation. 2014;97:413-8. Publication showing surfactant therapy can attenuate artificial aspiration-induced injury during EVLP.

40. Nakajima D, Liu M, Ohsumi A, Kalaf R, Iskender I, Hsin M, et al. Lung lavage and surfactant replacement during ex vivo lung perfusion for treatment of gastric acid aspiration-induced donor lung injury. J Hear Lung Transplant. 2017;36:577-85. Publication showing surfactant therapy can attenuate artificial aspirationinduced injury during EVLP.

41. Remund KF, Best M, Egan JJ. Infections relevant to lung transplantation. Proc Am Thorac Soc. 2009;6:94-100.

42. Andreasson A, Karamanou DM, Perry JD, Perry A, zalp F, Butt T, et al. The effect of ex vivo lung perfusion on microbial load in human donor lungs. J Hear Lung Transplant. 2014;33:910-6.

43. Nakajima D, Cypel M, Bonato R, Machuca TN, Iskender I, Hashimoto $\mathrm{K}$, et al. Ex vivo perfusion treatment of infection in human donor lungs. Am J Transplant. 2016;16:1229-37. Publication showing succesful treatment of human donor lungs using high dose antibiotics

44.• Zinne N, Krueger M, Hoeltig D, et al. Treatment of infected lungs by ex vivo perfusion with high dose antibiotics and autotransplantation: A pilot study in pigs. PLoS One. 2018; https://doi.org/10.1371/journal.pone.0193168. First animal study demonstrating EVLP followed by autotransplantation.

45. M a M, Folkesson HG, Clerici C. Lung epithelial fluid transport and the resolution of pulmonary edema. Physiol Rev. 2002;82:569-600.

46. Mutlu GM, Dumasius V, Burhop J, McShane P, Meng FJ, Welch L, et al. Upregulation of alveolar epithelial active $\mathrm{Na}+$ transport is dependent on beta2-adrenergic receptor signaling. Circ Res. 2004;94:1091-100. 
47. Lasnier JM, Wangensteen OD, Schmitz LS, Gross CR, Ingbar DH. Terbutaline stimulates alveolar fluid resorption in hyperoxic lung injury. J Appl Physiol. 1996;81:1723-9.

48. Frank JA, Briot R, Lee JW, Ishizaka A, Uchida T, Matthay MA. Physiological and biochemical markers of alveolar epithelial barrier dysfunction in perfused human lungs. Am J Physiol Lung Cell Mol Physiol. 2007;293:L52-9.

49. Valenza F, Rosso L, Coppola S, Froio S, Colombo J, Dossi R, et al. $\beta$-Adrenergic agonist infusion during extracorporeal lung perfusion: effects on glucose concentration in the perfusion fluid and on lung function. J Hear Lung Transplant. 2012;31:524-30.

50. Valenza F, Rosso L, Pizzocri M, Salice V, Umbrello M, Conte G, et al. The consumption of glucose during ex vivo lung perfusion correlates with lung edema. Transplant Proc. 2011;43:993-6.

51. Kondo T, Chen F, Ohsumi A, Hijiya K, Motoyama H, Sowa T, et al. $\beta 2$-Adrenoreceptor agonist inhalation during ex vivo lung perfusion attenuates lung injury. Ann Thorac Surg. 2015;100:480-6.

52. Oto T, Rabinov M, Griffiths AP, Whitford H, Levvey BJ, Esmore DS, Williams TJ, Snell GI (2005) Unexpected donor pulmonary embolism affects early outcomes after lung transplantation : A major mechanism of primary graft failure ? 1-9.

53. Machuca TN, Hsin MK, Ott HC, Chen M, Hwang DM, Cypel M, et al. Injury-specific ex vivo treatment of the donor lung: pulmonary thrombolysis followed by successful lung transplantation. Am J Respir Crit Care Med. 2013;188:878-80.

54. Luc JGY, Bozso SJ, Freed DH, Nagendran J. Successful repair of donation after circulatory death lungs with large pulmonary embolus using the lung organ care system for ex vivo thrombolysis and subsequent clinical transplantation. Transplantation. 2015;99:e1-2.

55. Inci I, Yamada Y, Hillinger S, Jungraithmayr W, Trinkwitz M, Weder W. Successful lung transplantation after donor lung reconditioning with urokinase in ex vivo lung perfusion system. Ann Thorac Surg. 2014;98:1837-8.

56. Snell GI, Griffiths A, Levvey BJ, Oto T. Availability of lungs for transplantation: exploring the real potential of the donor pool. J Hear Lung Transplant. 2008;27:662-7.

57. Reeb J, Keshavjee S, Cypel M. Expanding the lung donor pool: advancements and emerging pathways. Curr Opin Organ Transpl. 2015;20:498-505.

58. Cypel M, Levvey B, Van Raemdonck D, et al. International Society for Heart and Lung Transplantation donation after circulatory death registry report. J Hear lung Transplant. 2015;34:1278-82.

59. Mooney JJ, Hedlin H, Mohabir PK, Vazquez R, Nguyen J, Ha R, et al. Lung quality and utilization in controlled donation after circulatory determination of death within the United States. Am J Transplant. 2016;16:1207-15.

60. Gomez-De-Antonio D, Campo-Caaveral JL, Crowley S, Valdivia D, Cordoba M, Moradiellos J, et al. Clinical lung transplantation from uncontrolled nonheart-beating donors revisited. J Hear Lung Transplant. 2012;31:349-53.

61. Levvey BJ, Harkess M, Hopkins P, Chambers D, Merry C, Glanville AR, et al. Excellent clinical outcomes from a national donation-after-determination-of-cardiac-death lung transplant collaborative. Am J Transpl. 2012;12:2406-13.

62. Van De Wauwer C, Verschuuren EAM, van der Bij W, Nossent GD, Erasmus ME. The use of non-heart-beating lung donors category III can increase the donor pool. Eur J Cardio-thoracic Surg. 2011;39: e175-80.

63. De Vleeschauwer SI, Wauters S, Dupont LJ, Verleden SE, WillemsWidyastuti A, Vanaudenaerde BM, et al. Medium-term outcome after lung transplantation is comparable between brain-dead and cardiac-dead donors. J Hear Lung Transplant. 2011;30:975-81.
64. Puri V, Scavuzzo M, Guthrie T, Hachem R, Krupnick AS, Kreisel $\mathrm{D}$, et al. Lung transplantation and donation after cardiac death: a single center experience. In: Ann Thorac Surg 88:1609-14-5, vol. 88; 2009. p. 1609-15.

65. De Vleeschauwer S, Van Raemdonck D, Vanaudenaerde B, et al. Early outcome after lung transplantation from non-heart-beating donors is comparable to heart-beating donors. J Hear Lung Transplant. 2009;28:380-7.

66. Cypel M, Sato M, Yildirim E, Karolak W, Chen F, Yeung J, et al. Initial experience with lung donation after Cardiocirculatory death in Canada. J Hear Lung Transplant. 2009;28:753-8.

67. Mason DP, Thuita L, Alster JM, Murthy SC, Budev MM, Mehta $\mathrm{AC}$, et al. Should lung transplantation be performed using donation after cardiac death? The United States experience. J Thorac Cardiovasc Surg. 2008;136:1061-6.

68. Zych B, Popov AF, Amrani M, Bahrami T, Redmond KC, Krueger $\mathrm{H}$, et al. Lungs from donation after circulatory death donors: an alternative source to brain-dead donors? Midterm results at a single institution. Eur J Cardio-thoracic Surg. 2012;42:542-9.

69. de Antonio DG, Marcos R, Laporta R, Mora G, García-Gallo C, Gámez $\mathrm{P}$, et al. Results of clinical lung transplant from uncontrolled non-heart-beating donors. J Hear Lung Transplant. 2007;26:529 34.

70. Hernadez-Alejandro R, Wall W, Jevnikar A, Luke P, Sharpe M, Russell D, et al. Organ donation after cardiac death: donor and recipient outcomes after the first three years of the Ontario experience. Can J Anaesth. 2011;58:599-605.

71. Martens A, Montoli M, Faggi G, Katz I, Pype J, Vanaudenaerde $\mathrm{BM}$, et al. Argon and xenon ventilation during prolonged ex vivo lung perfusion. J Surg Res. 2016;201:44-52.

72. Kalaf-Mussi R, Lee J, Nakajima D, Chen M, Maahs L, Coutinho R, et al. Ex-vivo therapeutic use of carbon monoxide (CO) to improve donor lungs for transplantation. J Hear Lung Transplant. 2015;34: S $92-3$.

73. Haam S, Lee S, Paik HC, Park MS, Song JH, Lim BJ, et al. The effects of hydrogen gas inhalation during ex vivo lung perfusion on donor lungs obtained after cardiac death. Eur J Cardio-thoracic Surg. 2015;48:542-7.

74. Martens A, Boada M, Vanaudenaerde BM, Verleden SE, Vos R, Verleden GM, et al. Steroids can reduce warm ischemic reperfusion injury in a porcine DCD model with EVLP evaluation. Transpl Int. 2016;29:1237-46.

75. Inci I, Arni S, Acevedo C, Jungraithmayr W, Inci D, Vogt P, et al. Surfactant alterations following donation after cardiac death donor lungs. Transpl Int. 2011;24:78-84.

76. Inci I, Hillinger S, Arni S, Kaplan T, Inci D, Weder W. Reconditioning of an injured lung graft with intrabronchial surfactant instillation in an ex vivo lung perfusion system followed by transplantation. J Surg Res. 2013;184:1143-9.

77. Sun CX, Zhong H, Mohsenin A, Morschl E, Chunn JL, Molina JG, et al. Role of $\mathrm{A} 2 \mathrm{~B}$ adenosine receptor signaling in adenosinedependent pulmonary inflammation and injury. J Clin Invest. 2006;116:2173-82.

78. Huerter ME, Sharma AK, Zhao Y, Charles EJ, Kron IL, Laubach VE. Attenuation of pulmonary ischemia-reperfusion injury by adenosine A2BReceptor antagonism. Ann Thorac Surg. 2016;102:385-93.

79. Francioli C, Wang X, Parapanov R, Abdelnour E. Pyrrolidine dithiocarbamate administered during ex-vivo lung perfusion promotes rehabilitation of injured donor rat lungs obtained after prolonged warm ischemia. PLoS One. 2017;12:1-15. 